\title{
Modulatory Role of Simvastatin against Aluminium Chloride-Induced Behavioural and Biochemical Changes in Rats
}

\author{
Madhavan Nampoothiri, Jessy John, Nitesh Kumar, Jayesh Mudgal, \\ Gopalan Kutty Nampurath, and Mallikarjuna Rao Chamallamudi \\ Department of Pharmacology, Manipal College of Pharmaceutical Sciences, Manipal University, Manipal, Karnataka 576104, India \\ Correspondence should be addressed to Mallikarjuna Rao Chamallamudi; mallikin123@gmail.com
}

Received 21 October 2014; Revised 29 December 2014; Accepted 7 January 2015

Academic Editor: João Quevedo

Copyright (c) 2015 Madhavan Nampoothiri et al. This is an open access article distributed under the Creative Commons Attribution License, which permits unrestricted use, distribution, and reproduction in any medium, provided the original work is properly cited.

\begin{abstract}
Objectives. Aluminium, a neurotoxic agent in humans, has been implicated in the pathogenesis of neurodegenerative disorders. In this study, we examined the behavioral and biochemical effects of aluminium in rats with special emphasis on memory centres, namely, hippocampus and frontal cortex. Further, the effect of simvastatin treatment on aluminium intoxication was evaluated. Methods. Rats were exposed to aluminium chloride $\left(\mathrm{AlCl}_{3}\right)$ for 60 days. Simvastatin $(10 \mathrm{mg} / \mathrm{kg} /$ p.o. $)$ and rivastigmine $(1 \mathrm{mg} / \mathrm{kg} /$ p.o. $)$ were administered daily prior to $\mathrm{AlCl}_{3}$. Behavioral parameters were assessed using Morris water maze test and actophotometer followed by biochemical investigations, namely, acetylcholinesterase (AChE) activity, TNF- $\alpha$ level, antioxidant enzymes (GSH, catalase), lipid peroxidation, and nitrite level in hippocampus and frontal cortex. Triglycerides, total cholesterol, LDL, and HDL levels in serum were also determined. Key Findings. Simvastatin treatment improved cognitive function and locomotor activity in rats. Simvastatin reversed hyperlipidemia and significantly rectified the deleterious effect of $\mathrm{AlCl}_{3}$ on $\mathrm{AChE}$ activity. Further, in hippocampus and frontal cortex, aluminium-induced elevation in nitrite and TNF- $\alpha$ and reduction in antioxidant enzymes were inhibited by simvastatin. Conclusion. To conclude, the present study suggests that simvastatin per se protects the neurons in hippocampus and frontal cortex from $\mathrm{AlCl}_{3}$, an environmental toxin.
\end{abstract}

\section{Introduction}

Aluminium is the most abundant metal on the earth. It gets access to the human body through drinking water, food, use of utensils, deodorants, and drugs. In the brain, aluminium accumulates in sensitive areas such as hippocampus and frontal cortex and is considered a potential contributing factor to the pathogenesis of neurodegenerative disorders like Alzheimer's disease (AD) and Parkinson's disease (PD) [1-3]. Aluminium-mediated neurodegeneration resulting in cognitive dysfunction has been associated with elevated amyloid precursor protein (APP) expression $[4,5]$, amyloid $\beta(\mathrm{A} \beta)$ deposition $[6,7]$, impaired cholinergic projections $[8]$, apoptotic neuronal death $[9,10]$, and phosphorylated tau overexpression [11], which are also seen in $\mathrm{AD}$ patients. Thus, aluminium-induced cognitive deficit has been widely used for the preclinical testing of promising molecules against $\mathrm{AD}$ [12-14].
Current treatments only provide temporary and modest improvement in cognitive impairment and are considered symptomatic treatments. Thus, there is a need to develop novel and effective medication by focusing on alternative approaches, which go beyond acetylcholinesterase (AChE) inhibition and N-methyl-D-aspartate (NMDA) antagonism. Recent evidence indicates that prevalence of dementia is low among patients taking statins over a long period of time [15-17]. Contrary to this, there are clinical reports indicating that statins lead to cognitive impairment [18-20]. HMGCoA reductase (3-hydroxy-3-methylglutaryl-coenzyme Areductase) inhibitors (statins) are widely used as cholesterollowering agents. Besides cholesterol lowering, statins exert anti-inflammatory, antioxidant, and neuroprotective properties [21]. The literature also reports the potential of statins in modulating the amyloidogenic pathway $[22,23]$. A USFDA report on February 28, 2012, states that statins produce reversible dementia in some population. However, since these 
are isolated and rare observations, FDA advised patients to continue their statin medication to prevent cardiac damage. Thus, there is no clarity till today on the role of statins in dementia. In view of this, there is scope for the prospective investigation to ascertain the pharmacological actions of statins in the area of memory impairment and cognitive dysfunction. Among different statins, we have selected simvastatin on the basis of its high lipophilicity and ease of traversing the blood brain barrier [24]. To date, there are no reports on simvastatin against aluminium-mediated behavioural and biochemical changes in rats. Thus, the study was taken up to investigate the role of lipid lowering drug (simvastatin) in spatial memory and to elicit the possible mechanisms through which it modulates the cognitive deficit in aluminium exposed rats.

\section{Materials and Methods}

2.1. Animals. Ninety-day-old male Wistar rats, weighing 200-250 g, were used for the study. The animals were obtained from Central Animal Research Facility (CARF) of Manipal University, Manipal. For seven days prior to the experiment, the animals were acclimatized to laboratory conditions and were maintained under controlled temperature $\left(23 \pm 2^{\circ} \mathrm{C}\right)$ and humidity $(50 \pm 5 \%)$ conditions. Standard conditions of $12 \mathrm{~h}$ light/dark cycle were provided. The animals were kept in sanitized polypropylene cages having sterile paddy husk as bedding with free access to food and water. The experimental protocol was approved by the Institutional Animal Ethics Committee, Kasturba Medical College, Mani$\mathrm{pal}$ (IAEC/KMC/73/2012), and was carried out in accordance with the guidelines given by the Committee for the Purpose of Control and Supervision of Experiments on Animals (CPCSEA), Government of India.

2.2. Drugs and Chemicals. Acetylthiocholine iodide, reduced glutathione, thiobarbituric acid, griess reagent, hydrogen peroxide, and 5,5'-dithiobis-(2-nitrobenzoic acid) (DTNB) were obtained from Sigma-Aldrich Co. LLC (St. Louis, MO, USA). $\mathrm{AlCl}_{3}$ (Spectrochem Pvt. Limited, India), simvastatin (Biocon Ltd., India), and rivastigmine (Dr. Reddy's Laboratories, Hyderabad, India) were obtained. All chemicals used in this study were of analytical grade.

2.3. Experimental Design. On probe day (day 5), the animals were randomized based on ELT (escape latency) and divided into 6 groups $(n=8)$. $\mathrm{AlCl}_{3}$, simvastatin, and rivastigmine solutions were made freshly each day for administration. Rats were administered with $\mathrm{AlCl}_{3}(175 \mathrm{mg} / \mathrm{kg})$ orally from day 6 (i.e., $24 \mathrm{~h}$ after the completion of retention trial on day 5) for 60 days. Aluminium chloride was dissolved in distilled water and administered orally at a dose of $0.5 \mathrm{~mL} / 100 \mathrm{~g}$ bodyweight. The dose of $\mathrm{AlCl}_{3}$ was selected based on the previous literature reports $[25,26]$ and from a pilot study conducted. This dose was found to have a faster rate of induction with low incidence of mortality. Simvastatin $(10 \mathrm{mg} / \mathrm{kg})$ and the standard drug (rivastigmine $1 \mathrm{mg} / \mathrm{kg}$ ), suspended in $0.5 \%$ sodium carboxy methyl cellulose (CMC), were given orally, 45 minutes before $\mathrm{AlCl}_{3}$ administration for 60 days beginning on day 6. The dose selection was based on the previous literature reports [27-29]. Bodyweights of the animals were taken on daily basis throughout the study. The groups were as follows.

Group 1: normal control-received distilled water (5 mL/kg p.o.).

Group 2: vehicle control-received $0.5 \%$ CMC (5 mL/kg p.o.).

Group 3: $\mathrm{AlCl}_{3}$ (175 mg/kg p.o.).

Group 4: rivastigmine $(1 \mathrm{mg} / \mathrm{kg}$ p.o. $)+\mathrm{AlCl}_{3}$ (175 mg/kg p.o.).

Group 5: simvastatin (10 mg/kg p.o.) + $\mathrm{AlCl}_{3}$ (175 mg/kg p.o.).

2.4. Spatial Memory Assessment Using Morris Water Maze [30]. The water maze contained a circular water pool with $150 \mathrm{~cm}$ diameter and $40 \mathrm{~cm}$ height.

The water pool was divided into northeast (NE), southeast (SE), southwest (SW), and northwest (NW) equally spaced quadrants along the circumference of the pool. In the NW quadrant, an escape platform (10 cm diameter) was kept, $2 \mathrm{~cm}$ below the water surface. Throughout the acquisition trials the platform was maintained in a constant location in NW quadrant. The rats were trained to locate this hidden platform. If the rat failed to find the platform within $60 \mathrm{sec}$, it was gently guided to the platform and was allowed to stay there for $15 \mathrm{sec}$. Animals had four acquisition trials per day for four consecutive days. To eliminate the quadrant effects, animal was positioned in each quadrant during each trial. Animals that failed to reach the platform in $20 \mathrm{~s}$ on the 4 th trial day were excluded from the study. On probe day (day 5), $24 \mathrm{~h}$ after the last acquisition trial, escape platform was removed and retention trial was conducted. The animals were allowed to swim for $60 \mathrm{~s}$ before the end of session. Retention trials were repeated on day 65 on all groups to evaluate the memory consolidation. Data were obtained through a video camera attached to a computerized tracking system (Any Maze, Ugo Basile, Italy) fixed above the centre of the pool. Time to reach hidden platform (escape latency), latency to find the target quadrant (northwest latency), and percentage of time spent in target quadrant (NW) were measured during retention trials.

2.5. Locomotor Activity. Locomotor activity was assessed in animals using a digital photoactometer (INCO, Ambala, India). The ambulatory movements were recorded for a period of $10 \mathrm{~min}$ and expressed in terms of total photo beam counts for $10 \mathrm{~min}$ per animal [31]. Locomotor activity was assessed on 5th and 65th days before probe trial in Morris water maze.

2.6. Biochemical Evaluation. Animals were mildly anaesthetized at the end of the experimental period with diethyl ether and the blood samples were collected by retroorbital sinus puncture into microcentrifuge tubes.

Blood was allowed to clot for half an hour and then centrifuged at $10000 \mathrm{rpm}$ for 10 minutes to obtain serum. 
TABLE 1: Effect of simvastatin on serum lipid profile.

\begin{tabular}{lcccc}
\hline Treatment & $\begin{array}{c}\text { Total cholesterol } \\
(\mathrm{mg} / \mathrm{dL})\end{array}$ & $\begin{array}{c}\text { Triglycerides } \\
(\mathrm{mg} / \mathrm{dL})\end{array}$ & $\begin{array}{c}\text { LDL } \\
(\mathrm{mg} / \mathrm{dL})\end{array}$ & $\begin{array}{c}\mathrm{HDL} \\
(\mathrm{mg} / \mathrm{dL})\end{array}$ \\
\hline Normal control & $68.63 \pm 2.77$ & $66.67 \pm 1.93$ & $21.15 \pm 2.27$ & $43.03 \pm 1.10$ \\
Vehicle control & $62.25 \pm 4.36$ & $65.21 \pm 3.36$ & $19.95 \pm 2.19$ & $44.65 \pm 1.48$ \\
$\mathrm{AlCl}_{3}$ & $90.19 \pm 3.22^{*}$ & $110.9 \pm 9.85^{*}$ & $31.81 \pm 2.78^{*}$ & $30.19 \pm 0.98^{*}$ \\
$\mathrm{AlCl}_{3}+$ rivastigmine & $72.91 \pm 3.99$ & $72.45 \pm 7.58$ & $22.21 \pm 3.17$ & $31.68 \pm 2.00$ \\
$\mathrm{AlCl}_{3}+$ simvastatin & $55.12 \pm 3.54^{\#}$ & $60.81 \pm 2.04^{\#}$ & $11.76 \pm 2.37^{\#}$ & $42.12 \pm 3.27^{\#}$ \\
\hline
\end{tabular}

Effect of $\mathrm{AlCl}_{3}$ and $\mathrm{AlCl}_{3}+$ treatments on (a) total cholesterol, (b) triglycerides, (c) LDL, and (d) HDL. Data are presented as mean \pm SEM $(n=8) .{ }^{*} P<0.05$ as compared to control group and ${ }^{\#} P<0.05$ as compared to $\mathrm{AlCl}_{3}$ treated group.

Samples were divided into aliquots and stored at $-20^{\circ} \mathrm{C}$ until biochemical analysis.

The triglyceride (GPO-POD method), total cholesterol (CHOD-POD method), LDL, and HDL levels were estimated in samples by end point method as per the manufacturer's instructions with the help of diagnostic kits (Aspen Laboratories, Mumbai) using ELISA plate reader.

2.7. Dissection and Tissue Preparation. Immediately after the probe trial on day 65 , the animals were sacrificed by decapitation. On the dorsal side of the skull, an incision was made to expose and remove the brain rapidly from each rat. According to the method described by Glowinski and Iversen [32], hippocampus and frontal cortex were dissected. A $10 \% \mathrm{w} / \mathrm{v}$ homogenate of samples was prepared in ice-cold $0.1 \mathrm{M}$ phosphate buffer $\mathrm{pH} 7.4$ using an Ultra-Turrax T25 homogenizer at a speed of $9500 \mathrm{rpm}$.

2.8. Estimation of Acetylcholinesterase (AChE) Activity. The acetylcholinesterase activity was determined quantitatively by Ellman's method [33]. The enzyme activity was measured by following the increase of yellow colour produced from the reaction of thiocholine with $5,5^{\prime}$-dithiobis-(2-nitrobenzoic acid) $[\mathrm{DTNB}]$

2.9. Measurement of Endogenous Antioxidant Defence System. The homogenate was used for the estimation of nitrite [34], lipid peroxidation [35], catalase activity [36], and glutathione [37] in hippocampus and frontal cortex.

2.10. Estimation of Total Protein. Total protein was estimated in all tissue samples by using Pierce BCA Protein Assay Kit as per the experimental protocol given by Thermo Scientific, USA.

2.11. Tumor Necrosis Factor- $\alpha(T N F-\alpha)$ Estimation in Hippocampus. In the supernatant of the tissue homogenate, level of TNF- $\alpha$ was estimated by rat TNF- $\alpha$ enzyme linked immunosorbant assay (ELISA) kit as per the manufacturer's instruction given by Invitrogen Corporation, USA.

2.12. Statistical Analysis. Data were analyzed by one-way analysis of variance (ANOVA) followed by Tukey's post hoc test. Data were expressed as mean \pm standard error of the mean and the values of $P<0.05$ were considered statistically significant.

\section{Results}

3.1. Simvastatin Attenuated $\mathrm{AlCl}_{3}$-Induced Spatial Memory Deficit in Rats. After 60 days of $\mathrm{AlCl}_{3}$ intoxication in rats, significant spatial memory impairment was observed in Morris water maze test during the retention trial conducted on the 60th day (Figure 1). $\mathrm{AlCl}_{3}(175 \mathrm{mg} / \mathrm{kg}$ p.o.) treatment significantly $(P<0.05)$ raised ELT (Figure $1(\mathrm{a}))$ and NW latency (Figure 1(b)). During the probe trial on day 60, aluminium treated animals were found to spend significantly less time in the target quadrant (NW) than the control group (Figure 1(c)). Throughout the study, no significant change was found in the body weights among the treated groups (Figure $1(\mathrm{~d})$ ). The spatial memory deficit caused by $\mathrm{AlCl}_{3}$ was significantly $(P<0.05)$ reversed by simvastatin and rivastigmine (Figures $1(\mathrm{a}), 1(\mathrm{~b})$, and $1(\mathrm{c})$ ).

3.2. Effect of Simvastatin on Locomotor Activity of Rats. As shown in Figure 2, a significant reduction in the locomotor activity was observed in the animals of $\mathrm{AlCl}_{3}$ treated group after 60 days of treatment as compared to control animals. On the 65th day, the drug treatments (simvastatin and rivastigmine) significantly $(P<0.05)$ produced increased locomotor activity of animals as compared with $\mathrm{AlCl}_{3}$ group.

3.3. Simvastatin Reversed $\mathrm{AlCl}_{3}$-Induced Lipid Profile Alterations in Rats. $\mathrm{AlCl}_{3}$ produced significant $(P<0.05)$ upsurge in total cholesterol, triglycerides, and low-density lipoprotein (LDL) levels and significantly decreased serum high-density lipoprotein (HDL) levels compared with control group (Table 1). Simvastatin-treated group, but not the rivastigmine-treated group, reversed the elevation in lipid profile induced $\mathrm{AlCl}_{3}$ (Table 1).

3.4. Reversal of Diminished Acetylcholinesterase Activity by Simvastatin. Sixty days of chronic $\mathrm{AlCl}_{3}$ exposure significantly reduced AChE activity in the frontal cortex $(P<$ $0.05)$ and hippocampus $(P<0.05)$ of rats as compared to normal control. In hippocampus and frontal cortex, AChE activity was significantly $(P<0.05)$ lowered by rivastigmine compared to control group. The effect of $\mathrm{AlCl}_{3}$ on $\mathrm{AChE}$ 


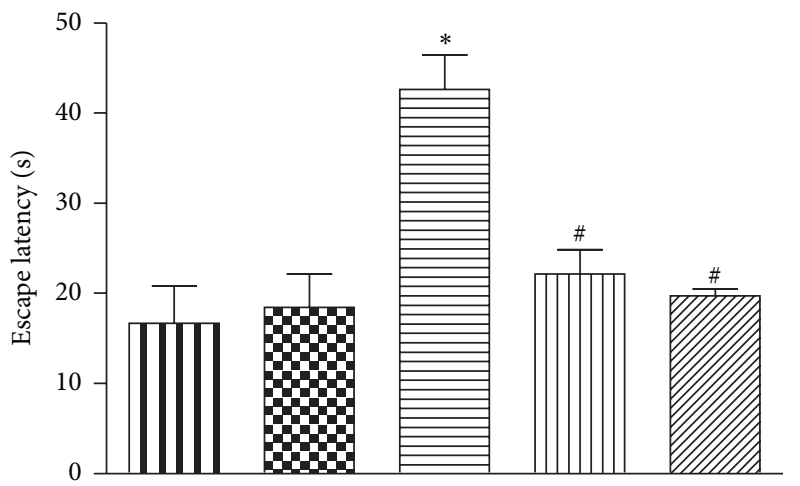

(a)

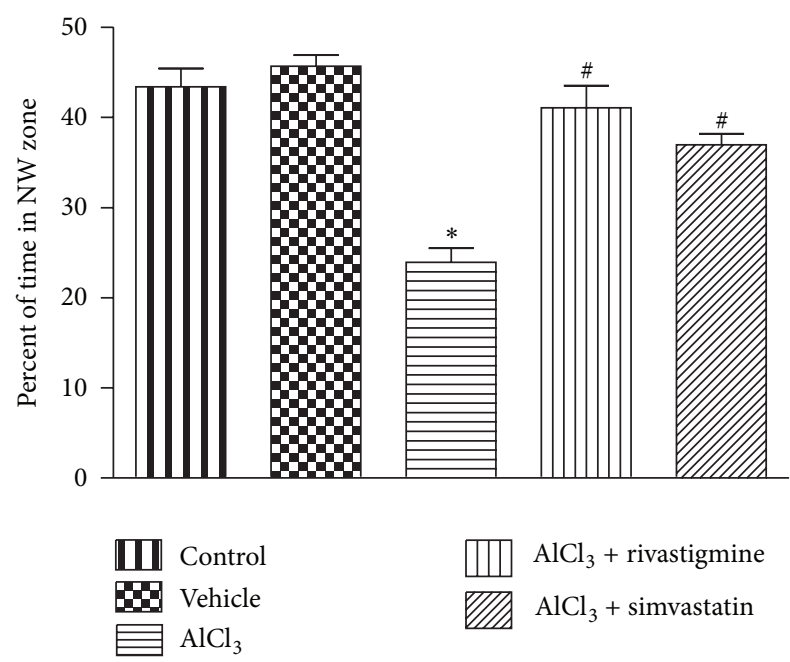

(c)

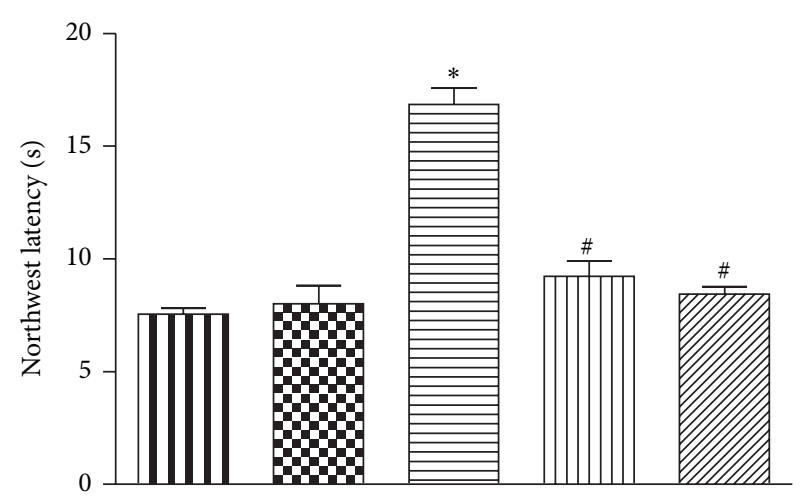

(b)

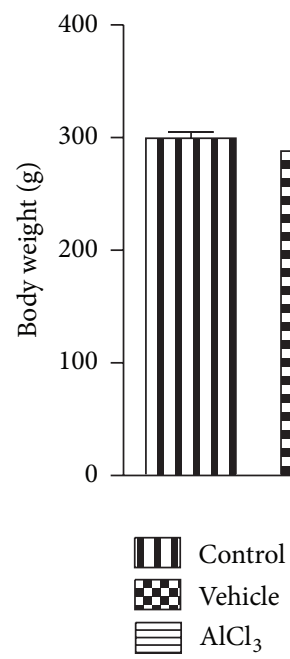

Figure 1: Effect of $\mathrm{AlCl}_{3}$ and $\mathrm{AlCl}_{3}$ + treatments on (a) escape latency time (latency to reach platform), (b) northwest latency, (c) percent of time spent in target quadrant (NW), and (d) body weight during retention trial after treatment. Data are presented as mean \pm SEM $(n=8)$. ${ }^{*} P<0.05$ as compared to control group and ${ }^{\#} P<0.05$ as compared to $\mathrm{AlCl}_{3}$ treated group.

activity was significantly inhibited by $10 \mathrm{mg} / \mathrm{kg}$ simvastatin (Tables 2 and 3).

3.5. Attenuation of Elevated MDA and Nitrite Level by Simvastatin. In aluminium treated rats, levels of malondialdehyde (MDA) and nitrite in hippocampus and frontal cortex recorded a significant increase as compared with control group. Both rivastigmine and simvastatin $(10 \mathrm{mg} / \mathrm{kg})$ significantly reversed the elevated MDA and nitrite levels. Interestingly, simvastatin at $10 \mathrm{mg} / \mathrm{kg}$ showed a better reduction of MDA levels than rivastigmine in hippocampus region (Tables 2 and 3 ).

3.6. Elevation of Antioxidant Enzyme (Catalase, GSH) Levels by Simvastatin. The hippocampus and frontal cortex of the $\mathrm{AlCl}_{3}$ treated rats showed significant $(P<0.05)$ decrease in catalase and glutathione activity. Rivastigmine $(1 \mathrm{mg} / \mathrm{kg})$ and simvastatin $(10 \mathrm{mg} / \mathrm{kg})$ significantly improved the catalase and glutathione (GSH) levels as compared to $\mathrm{AlCl}_{3}$ treated group (Tables 2 and 3 ).
3.7. Simvastatin Inhibited TNF- $\alpha$ Level in Hippocampus of Rats. A threefold increase in TNF- $\alpha$ level was found in $\mathrm{AlCl}_{3}$ treated rats, whereas simvastatin $(10 \mathrm{mg} / \mathrm{kg})$ and rivastigmine significantly $(P<0.05)$ inhibited this rise in TNF- $\alpha$ levels (Figure 3).

\section{Discussion}

The study explores the protective effect of HMG Co-A reductase inhibitor, simvastatin, on $\mathrm{AlCl}_{3}$-induced behavioural and neurochemical changes in rats. After chronic exposure, aluminium accumulates in all brain regions with greater accumulation in cortex and hippocampus $[38,39]$. Hippocampus and frontal cortex play an important role in learning and memory [40], which is severely affected in neurodegenerative disorders such as AD and PD.

Chronic aluminium exposure has been reported to result in cognitive [41] and locomotor impairment [42]. The cognitive deficit is evident from declined performance in Morris water maze test [43], passive avoidance task [44], and radial arm maze test [41]. In our study, aluminium treated rats 
TABLE 2: Effect of simvastatin on $\mathrm{AlCl}_{3}$-induced biochemical changes on frontal cortex.

\begin{tabular}{lccccc}
\hline Treatment & $\begin{array}{c}\text { MDA (nmol/mg } \\
\text { of protein) }\end{array}$ & $\begin{array}{c}\text { Nitrite } \\
\text { (nmol/mg of } \\
\text { protein) }\end{array}$ & $\begin{array}{c}\text { Reduced glutathione } \\
(\mu \mathrm{mol} / \mathrm{mg} \text { of } \\
\text { protein) }\end{array}$ & $\begin{array}{c}\text { Catalase }(\mu \mathrm{mol} \\
\text { of } \mathrm{H}_{2} \mathrm{O}_{2} \text { decom- } \\
\text { posed/min/mg } \\
\text { of protein) }\end{array}$ & $\begin{array}{c}\text { AChE }(\mu \mathrm{moles} \text { of } \\
\text { acetylthiocholine iodide } \\
\text { hydrolyzed/min/mg of } \\
\text { protein) }\end{array}$ \\
\hline Normal control & $0.085 \pm 0.0129$ & $1.71 \pm 0.248$ & $0.117 \pm 0.0075$ & $35.29 \pm 1.64$ & $0.0292 \pm 0.0018$ \\
Vehicle control & $0.074 \pm 0.0070$ & $1.87 \pm 0.098$ & $0.114 \pm 0.0053$ & $36.35 \pm 2.61$ & $0.0281 \pm 0.0017$ \\
$\mathrm{AlCl}_{3}$ & $0.209 \pm 0.0047^{*}$ & $3.75 \pm 0.102^{*}$ & $0.067 \pm 0.0022^{*}$ & $6.97 \pm 0.38^{*}$ & $0.0141 \pm 0.0014^{*}$ \\
$\mathrm{AlCl}_{3}+$ rivastigmine & $0.126 \pm 0.0077^{\#}$ & $2.32 \pm 0.170^{\#}$ & $0.104 \pm 0.0031^{\#}$ & $28.38 \pm 3.18^{\#}$ & $0.0094 \pm 0.0021^{\#}$ \\
$\mathrm{AlCl}_{3}+$ simvastatin & $0.125 \pm 0.0225^{\#}$ & $2.06 \pm 0.073^{\#}$ & $0.101 \pm 0.0026^{\#}$ & $24.39 \pm 4.51^{\#}$ & $0.0285 \pm 0.0022^{\#}$ \\
\hline
\end{tabular}

Effect of $\mathrm{AlCl}_{3}$ and $\mathrm{AlCl}_{3}$ + treatments on frontal cortex (a) MDA, (b) nitrite level, (c) glutathione (GSH) level, (d) catalase activity, and (e) acetylcholinesterase activity. Data are presented as mean \pm SEM $(n=8) .{ }^{*} P<0.05$ as compared to control group and ${ }^{\#} P<0.05$ as compared to $\mathrm{AlCl}_{3}$ treated group.

TABLE 3: Effect of simvastatin on $\mathrm{AlCl}_{3}$-induced biochemical changes on hippocampus.

\begin{tabular}{lccccc}
\hline Treatment & $\begin{array}{c}\text { MDA (nmol/mg } \\
\text { of protein) }\end{array}$ & $\begin{array}{c}\text { Nitrite } \\
\text { (nmol/mg of } \\
\text { protein) }\end{array}$ & $\begin{array}{c}\text { Reduced glutathione } \\
(\mu \mathrm{mol} / \mathrm{mg} \text { of } \\
\text { protein) }\end{array}$ & $\begin{array}{c}\text { Catalase }(\mu \mathrm{mol} \\
\text { of } \mathrm{H}_{2} \mathrm{O}_{2} \text { decom- } \\
\text { posed/min/mg } \\
\text { of protein) }\end{array}$ & $\begin{array}{c}\text { AChE }(\mu \mathrm{moles} \text { of } \\
\text { acetylthiocholine iodide } \\
\text { hydrolyzed/min/mg of } \\
\text { protein) }\end{array}$ \\
\hline Normal control & $0.091 \pm 0.0138$ & $1.64 \pm 0.090$ & $0.110 \pm 0.0036$ & $22.80 \pm 1.57$ & $0.0251 \pm 0.0016$ \\
Vehicle control & $0.091 \pm 0.0073$ & $1.87 \pm 0.373$ & $0.099 \pm 0.0036$ & $23.40 \pm 1.71$ & $0.0261 \pm 0.0017$ \\
$\mathrm{AlCl}_{3}$ & $0.206 \pm 0.0106^{*}$ & $3.86 \pm 0.137^{*}$ & $0.053 \pm 0.0010^{*}$ & $4.77 \pm 0.61^{*}$ & $0.0074 \pm 0.0021^{*}$ \\
$\mathrm{AlCl}_{3}+$ rivastigmine & $0.143 \pm 0.0119^{\#}$ & $1.95 \pm 0.249^{\#}$ & $0.084 \pm 0.0043^{\#}$ & $15.50 \pm 1.43^{\#}$ & $0.0060 \pm 0.0011^{\#}$ \\
$\mathrm{AlCl}_{3}+$ simvastatin & $0.182 \pm 0.0114^{\#}$ & $1.96 \pm 0.435^{\#}$ & $0.086 \pm 0.0044^{\#}$ & $12.11 \pm 1.26^{\#}$ & $0.0230 \pm 0.0016^{\#}$ \\
\hline
\end{tabular}

Effect of $\mathrm{AlCl}_{3}$ and $\mathrm{AlCl}_{3}+$ treatments on hippocampus (a) MDA, (b) nitrite level, (c) glutathione (GSH) level, (d) catalase activity, and (e) acetylcholinesterase activity. Data are presented as mean $\pm \operatorname{SEM}(n=8) .{ }^{*} P<0.05$ as compared to control group and ${ }^{\sharp} P<0.05$ as compared to $\mathrm{AlCl}_{3}$ treated group.

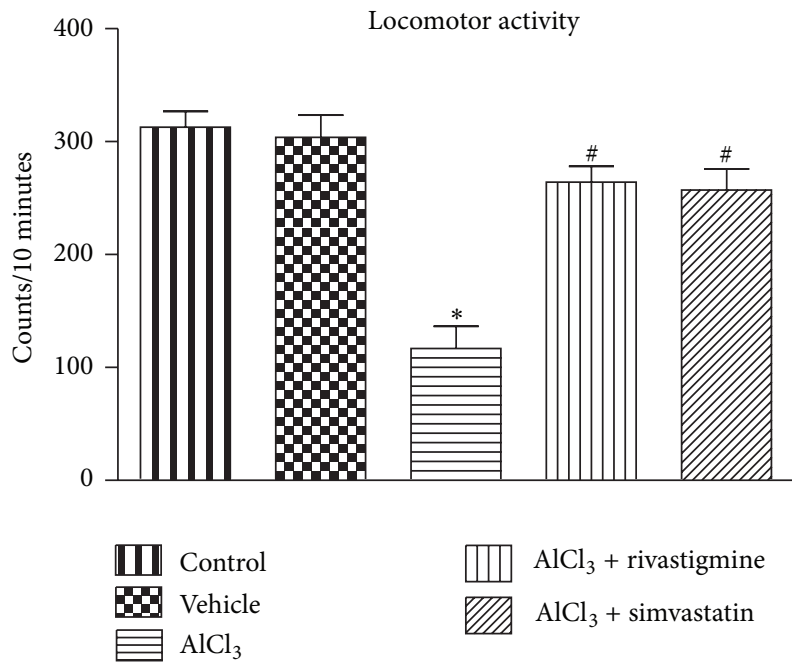

Figure 2: Effect of $\mathrm{AlCl}_{3}$ and $\mathrm{AlCl}_{3}+$ treatments on locomotor activity after treatment. Data are presented as mean \pm SEM $(n=8)$. ${ }^{*} P<0.05$ as compared to control group and ${ }^{\#} P<0.05$ as compared to $\mathrm{AlCl}_{3}$ treated group.

displayed behavioural alterations, which are consistent with the previous reports. In water maze test, $\mathrm{AlCl}_{3}$ treatment resulted in behavioural changes such as spatial memory deficit, indicated by increased escape latency, northwest latency, and decreased percentage of time spent in NW zone.

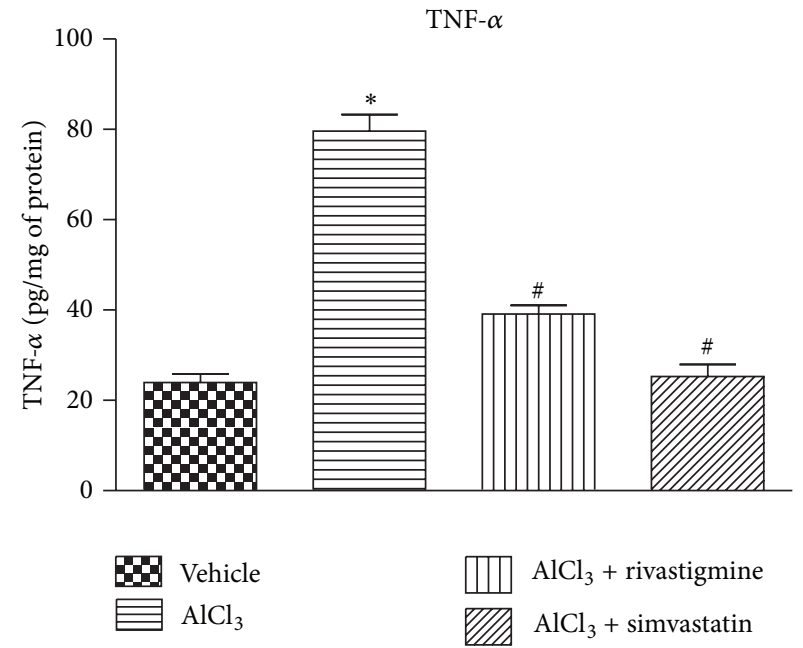

Figure 3: Effect of $\mathrm{AlCl}_{3}$ and $\mathrm{AlCl}_{3}$ + treatments on TNF- $\alpha$ level in the hippocampus of rats. Data are presented as mean $\pm \operatorname{SEM}(n=8)$. ${ }^{*} P<0.05$ as compared to control group and ${ }^{\#} P<0.05$ as compared to $\mathrm{AlCl}_{3}$ treated group.

Rivastigmine $(1 \mathrm{mg} / \mathrm{kg})$ and simvastatin $(10 \mathrm{mg} / \mathrm{kg})$ antagonized the spatial memory deficit caused by aluminium. This suggests the neuroprotective role of simvastatin in correcting cognitive dysfunction associated with aluminium exposure. Throughout the treatment period no significant changes were observed in body weight and health status of animals. 
Assessment of locomotor activity is a requirement for evaluating any possible CNS depressant/stimulant effect of interventions on animals. Similar to previous reports [42], a decline in locomotor activity in aluminium treated rats was observed, indicating the CNS depressant effect of chronic aluminium exposure. Thus, the overall cognitive behavioural changes by aluminium intoxication could be interlinked to locomotor impairment due to CNS depression. However, the impaired cholinergic transmission, oxidative/nitrergic stress, neuroinflammation, and dyslipidemia observed in aluminium exposed rats suggest that the cognitive deficit is the compounding effect of the above biochemical changes along with locomotor incoordination. Treatment with rivastigmine and simvastatin corrected the locomotor incoordination caused by $\mathrm{AlCl}_{3}$. These findings imply the ability of simvastatin to correct the aluminium-mediated behavioural changes.

Impaired cholinergic transmission is one of the factors implicated in the etiopathogenesis of memory deficit in $\mathrm{AD}$. The neurodegeneration in frontal cortex and hippocampus areas of the brain [45] resulting in impaired cholinergic transmission occurs by two ways. Firstly, in AD patients, it occurs either due to (i) decline in acetylcholine (ACh) release or due to (ii) decreased choline acetyltransferase activity, which results in the scarcity of ACh [46-48]. Secondly, elevated acetylcholinesterase (AChE) enzyme further adds to scarcity of $\mathrm{ACh}$ at synapse by degrading the available $\mathrm{ACh}$. This degradation of $\mathrm{ACh}$ is abolished by rivastigmine (AChE inhibitor) and, thus, is found effective in AD through improvement in cholinergic transmission. On the contrary, the literature also reports the reduced acetylcholinesterase activity in $\mathrm{AD}$ patients as compared with the normal $[49,50]$.

In the present study, $\mathrm{AlCl}_{3}$ inhibited acetylcholinesterase activity. Aluminium is a metal known to cause oxidative stress. Generally, oxidative stress has got the highest ability to cause damage to the highly active enzymes. Perhaps this property of $\mathrm{AlCl}_{3}$ might have produced the anticholinesterase activity observed in the present study with $\mathrm{AlCl}_{3}$. This observation corroborates with earlier workers [51,52] who observed a biphasic response, namely, rise in AChE activity in short phase and a marked decline in AChE enzyme activity on long term administration. In consistence with the above reports, the present work demonstrated the second phase, that is, decline in AChE enzyme activity after chronic administration (60 days) of aluminium to rats. We assume that decreased AChE activity is due to the slow accumulation of aluminium in the brain and formation of aluminium complex with high affinity for the anionic site of enzyme [51, 52], leading to induction of oxidative stress to inhibit AChE enzyme activity. However, it is intriguing how an agent $\left(\mathrm{AlCl}_{3}\right)$ observed to have anticholinesterase activity should cause $\mathrm{AD}$. We hypothesize that $\mathrm{AlCl}_{3}$ is a neurotoxin; therefore it has the propensity to cause impaired cholinergic transmission by affecting the synthesis and release. These effects are more pronounced than AChE inhibition which may be partial. This is true because the AChE inhibitory activity of standard drug rivastigmine in our study was found to be more significant than $\mathrm{AlCl}_{3}$ activity. On the other hand, simvastatin did not possess any acetylcholinesterase inhibition mechanism in vivo but abolished the effect of aluminium on acetylcholinesterase enzyme.

Elevated total serum cholesterol and LDL-associated cholesterol have been implicated in $\mathrm{AD}$ patients [53-55]. Even though the brain cholesterol is independent of the peripheral cholesterol stores, several reports suggest the correlation between elevated peripheral cholesterol and AD. In the present study, aluminium exposed rats showed elevated levels of total cholesterol and LDL and decreased HDL levels in serum, which was found to be correlated with cognitive dysfunction. The dyslipidemia may be due to aluminium accumulation in the liver as reported earlier [56, 57]. As expected, chronic treatment of aluminium exposed rats with simvastatin, a HMG-CoA reductase inhibitor, reversed the altered lipid profile. These results suggest the ameliorative role of simvastatin in dementia through correction of dyslipidemia. However, rivastigmine failed to correct the altered lipid profile parameters induced by aluminium.

The literature reports the contribution of oxidative stress and neuroinflammation to the pathogenesis of neurodegenerative disorders $[58,59]$. In $\mathrm{AlCl}_{3}$-induced cognitive dysfunction model, elevation of reactive oxygen species (ROS) level due to significant impairment of antioxidant enzyme system has been reported [43]. In the present study, $\mathrm{AlCl}_{3}$ treatment resulted in decrease in the levels of endogenous antioxidant enzymes like catalase and GSH in hippocampus and frontal cortex regions. Further, elevation of nitrite and malondialdehyde levels was also observed in these regions of aluminium exposed rats. The alterations in the antioxidant defence system like catalase, GSH, nitrite, and MDA levels were brought to normal by both rivastigmine and simvastatin treatment. Aluminium exposure augmented the elevation in hippocampus TNF- $\alpha$, a proinflammatory mediator. The elevated hippocampus TNF- $\alpha$ stimulates microglia to release glutamate, which causes excitotoxicity $[59,60]$. The rise in TNF- $\alpha$ was counteracted by treatment with rivastigmine and simvastatin. These results indicated the potential of simvastatin in preventing oxidative stress and neuroinflammation, thereby correcting the cognitive dysfunction. Future studies will be directed to study the role of TNF- $\alpha$ in frontal cortex along with hippocampus to link the possible mechanism of neuroinflammation mediated cognitive dysfunction.

\section{Conclusion}

Simvastatin exerted neuroprotective action against $\mathrm{AlCl}_{3}$ induced behavioural parameters such as cognitive deficit and locomotor impairment. Further, aluminium-mediated biochemical changes were reversed, where simvastatin was able to correct hyperlipidemia, oxidative stress, and neuroinflammation in hippocampus and cortex regions. Further studies are warranted to explore the link between $\mathrm{AlCl}_{3}$-mediated hyperlipidemia and associated dementia to establish the role of simvastatin in neuronal disturbances.

\section{Conflict of Interests}

The authors declare that they have no conflict of interests. 


\section{Acknowledgments}

The authors thank Manipal College of Pharmaceutical Sciences, Manipal, India, and Manipal University for providing research facility and Department of Science (FIST Scheme) for providing infrastructural support.

\section{References}

[1] A. Campbell, "The potential role of aluminium in Alzheimer's disease," Nephrology Dialysis Transplantation, vol. 17, supplement 2, pp. 17-20, 2002.

[2] T. P. Flaten, "Aluminium as a risk factor in Alzheimer's disease, with emphasis on drinking water," Brain Research Bulletin, vol. 55, no. 2, pp. 187-196, 2001.

[3] D. R. McLachlan, "Aluminium and the risk for Alzheimer's disease," Environmetrics, vol. 6, no. 3, pp. 233-275, 1995.

[4] R. Lin, X. Chen, W. Li, Y. Han, P. Liu, and R. Pi, "Exposure to metal ions regulates mRNA levels of APP and BACE1 in PC12 cells: blockage by curcumin," Neuroscience Letters, vol. 440, no. 3, pp. 344-347, 2008.

[5] J. R. Walton and M.-X. Wang, "APP expression, distribution and accumulation are altered by aluminum in a rodent model for Alzheimer's disease," Journal of Inorganic Biochemistry, vol. 103, no. 11, pp. 1548-1554, 2009.

[6] A. Campbell, A. Kumar, F. G. la Rosa, K. N. Prasad, and S. C. Bondy, "Aluminum increases levels of beta-amyloid and ubiquitin in neuroblastoma but not in glioma cells," Proceedings of the Society for Experimental Biology and Medicine, vol. 223, no. 4, pp. 397-402, 2000.

[7] M. Kawahara, M. Kato, and Y. Kuroda, "Effects of aluminum on the neurotoxicity of primary cultured neurons and on the aggregation of $\beta$-amyloid protein," Brain Research Bulletin, vol. 55, no. 2, pp. 211-217, 2001.

[8] K. Gulya, Z. Rakonczay, and P. Kása, "Cholinotoxic effects of aluminum in rat brain," Journal of Neurochemistry, vol. 54, no. 3, pp. 1020-1026, 1990.

[9] O. Ghribi, M. M. Herman, M. S. Forbes, D. A. DeWitt, and J. Savory, "GDNF protects against aluminum-induced apoptosis in rabbits by upregulating Bcl-2 and Bcl-X L and inhibiting mitochondrial Bax translocation," Neurobiology of Disease, vol. 8, no. 5, pp. 764-773, 2001.

[10] M. Kawahara, M. Kato-Negishi, R. Hosoda, L. Imamura, M. Tsuda, and Y. Kuroda, "Brain-derived neurotrophic factor protects cultured rat hippocampal neurons from aluminum maltolate neurotoxicity," Journal of Inorganic Biochemistry, vol. 97, no. 1, pp. 124-131, 2003.

[11] A. H. El-Sebae, M. E. Abdel-Ghany, D. Shalloway, M. M. A. Zeid, J. Blancato, and M. A. Saleh, "Aluminum interaction with human brain tau protein phosphorylation by various kinases," Journal of Environmental Science and Health B, vol. 28, no. 6, pp. 763-777, 1993.

[12] B. Wang, W. Xing, Y. Zhao, and X. Deng, "Effects of chronic aluminum exposure on memory through multiple signal transduction pathways," Environmental Toxicology and Pharmacology, vol. 29, no. 3, pp. 308-313, 2010.

[13] P. Sethi, A. Jyoti, R. Singh, E. Hussain, and D. Sharma, "Aluminium-induced electrophysiological, biochemical and cognitive modifications in the hippocampus of aging rats," NeuroToxicology, vol. 29, no. 6, pp. 1069-1079, 2008.
[14] D. Ribes, M. T. Colomina, P. Vicens, and J. L. Domingo, "Impaired spatial learning and unaltered neurogenesis in a transgenic model of alzheimer's disease after oral aluminum exposure," Current Alzheimer Research, vol. 7, no. 5, pp. 401-408, 2010.

[15] C. Cramer, M. N. Haan, S. Galea, K. M. Langa, and J. D. Kalbfleisch, "Use of statins and incidence of dementia and cognitive impairment without dementia in a cohort study," Neurology, vol. 71, no. 5, pp. 344-350, 2008.

[16] B. Mcguinness, J. O’Hare, D. Craig, R. Bullock, R. Malouf, and P. Passmore, "Statins for the treatment of dementia," Cochrane Database of Systematic Reviews, no. 8, Article ID CD007514, 2010.

[17] D. L. Sparks, R. J. Kryscio, M. N. Sabbagh, D. J. Connor, L. M. Sparks, and C. Liebsack, "Reduced risk of incident AD with elective statin use in a clinical trial cohort," Current Alzheimer Research, vol. 5, no. 4, pp. 416-421, 2008.

[18] H. H. Feldman, R. S. Doody, M. Kivipelto et al., "Randomized controlled trial of atorvastatin in mild to moderate Alzheimer disease: LEADe," Neurology, vol. 74, no. 12, pp. 956-964, 2010.

[19] M. Sano, K. L. Bell, D. Galasko et al., "A randomized, doubleblind, placebo-controlled trial of simvastatin to treat Alzheimer disease," Neurology, vol. 77, no. 6, pp. 556-563, 2011.

[20] S. Trompet, P. van Vliet, A. J. M. de Craen et al., "Pravastatin and cognitive function in the elderly. Results of the PROSPER Study," Journal of Neurology, vol. 257, no. 1, pp. 85-90, 2010.

[21] D. A. Butterfield, E. Barone, and C. Mancuso, "Cholesterolindependent neuroprotective and neurotoxic activities of statins: perspectives for statin use in Alzheimer disease and other age-related neurodegenerative disorders," Pharmacological Research, vol. 64, no. 3, pp. 180-186, 2011.

[22] K. Fassbender, M. Simons, C. Bergmann et al., "Simvastatin strongly reduces levels of Alzheimer's disease beta-amyloid peptides Abeta 42 and Abeta 40 in vitro and in vivo," Proceedings of the National Academy of Sciences of the United States of America, vol. 10, pp. 5856-5861, 2001.

[23] K. Höglund, A. Wallin, and K. Blennow, "Effect of statins on $\beta$-amyloid metabolism in humans: potential importance for the development of senile plaques in Alzheimer's disease," Acta Neurologica Scandinavica, vol. 114, no. 185, pp. 87-92, 2006.

[24] S. Sierra, M. C. Ramos, P. Molina, C. Esteo, J. A. Vázquez, and J. S. Burgos, "Statins as neuroprotectants: a comparative in vitro study of lipophilicity, blood-brain-barrier penetration, lowering of brain cholesterol, and decrease of neuron cell death," Journal of Alzheimer's Disease, vol. 23, no. 2, pp. 307-318, 2011.

[25] A. Kumar, A. Prakash, and S. Dogra, "Neuroprotective effect of carvedilol against aluminium induced toxicity: possible behavioral and biochemical alterations in rats," Pharmacological Reports, vol. 63, no. 4, pp. 915-923, 2011.

[26] P. Sharma, Z. Ahmad Shah, A. Kumar, F. Islam, and K. P. Mishra, "Role of combined administration of Tiron and glutathione against aluminum-induced oxidative stress in rat brain," Journal of Trace Elements in Medicine and Biology, vol. 21, no. 1, pp. 6370, 2007.

[27] S. W. Bihaqi, M. Sharma, A. P. Singh, and M. Tiwari, "Neuroprotective role of Convolvulus pluricaulis on aluminium induced neurotoxicity in rat brain," Journal of Ethnopharmacology, vol. 124, no. 3, pp. 409-415, 2009.

[28] P. Kumar and A. Kumar, "Protective effect of rivastigmine against 3-nitropropionic acid-induced Huntington's disease like symptoms: possible behavioural, biochemical and cellular 
alterations," European Journal of Pharmacology, vol. 615, no. 13, pp. 91-101, 2009.

[29] L. Cibickova, H. Radomir, M. Stanislav et al., "The influence of simvastatin, atorvastatin and high-cholesterol diet on acetylcholinesterase activity, amyloid beta and cholesterol synthesis in rat brain," Steroids, vol. 74, no. 1, pp. 13-19, 2009.

[30] R. Morris, "Developments of a water-maze procedure for studying spatial learning in the rat," Journal of Neuroscience Methods, vol. 11, no. 1, pp. 47-60, 1984.

[31] S. Kulkarni, "Experiment no. 4.4: to study CNS depressant property of chlorpromazine on locomotor activity of mice using actophotometer," in Handbook of Experimental Pharmacology, pp. 117-119, 1999.

[32] J. Glowinski and L. L. Iversen, "Regional studies of catecholamines in the rat brain. I. The disposition of $\left[{ }^{3} \mathrm{H}\right]$ norepinephrine, $\left[{ }^{3} \mathrm{H}\right]$ dopamine and $\left[{ }^{3} \mathrm{H}\right]$ dopa in various regions of the brain," Journal of Neurochemistry, vol. 13, no. 8, pp. 655-669, 1966.

[33] G. L. Ellman, K. D. Courtney, V. Andres Jr., and R. M. Featherstone, "A new and rapid colorimetric determination of acetylcholinesterase activity," Biochemical Pharmacology, vol. 7, no. 2, pp. 88-95, 1961.

[34] D. S. Bredt and S. H. Snyder, "Nitric oxide: a physiologic messenger molecule," Annual Review of Biochemistry, vol. 63, pp. 175-195, 1994.

[35] A. W. T. Konings and E. B. Drijver, "Radiation effects on membranes. I. Vitamin E deficiency and lipid peroxidation," Radiation Research, vol. 80, no. 3, pp. 494-501, 1979.

[36] H. Aebi, "Catalase in vitro," Methods in Enzymology, vol. 105, pp. 121-126, 1984.

[37] M. S. Moron, J. W. Depierre, and B. Mannervik, "Levels of glutathione, glutathione reductase and glutathione $S$-transferase activities in rat lung and liver," Biochimica et Biophysica Acta (BBA)_General Subjects, vol. 582, no. 1, pp. 67-78, 1979.

[38] R. Deloncle and O. Guillard, "Mechanism of Alzheimer's disease: arguments for a neurotransmitter-aluminium complex implication," Neurochemical Research, vol. 15, no. 12, pp. 12391245, 1990.

[39] D. Julka, R. K. Vasishta, and K. D. Gill, "Distribution of aluminum in different brain regions and body organs of rat," Biological Trace Element Research, vol. 52, no. 2, pp. 181-192, 1996.

[40] R. L. Buckner, W. M. Kelley, and S. E. Petersen, "Frontal cortex contributes to human memory formation," Nature Neuroscience, vol. 2, no. 4, pp. 311-314, 1999.

[41] R. A. Abdel-Aal, A.-A. A. Assi, and B. B. Kostandy, "Rivastigmine reverses aluminum-induced behavioral changes in rats," European Journal of Pharmacology, vol. 659, no. 2-3, pp. 169176, 2011.

[42] H. Erazi, W. Sansar, S. Ahboucha, and H. Gamrani, "Aluminum affects glial system and behavior of rats," Comptes Rendus Biologies, vol. 333, no. 1, pp. 23-27, 2010.

[43] K. A. Khan, N. Kumar, P. G. Nayak et al., "Impact of caffeic acid on aluminium chloride-induced dementia in rats," Journal of Pharmacy and Pharmacology, vol. 65, no. 12, pp. 1745-1752, 2013.

[44] P. Bhalla, M. L. Garg, and D. K. Dhawan, "Protective role of lithium during aluminium-induced neurotoxicity," Neurochemistry International, vol. 56, no. 2, pp. 256-262, 2010.

[45] P. T. Francis, A. M. Palmer, M. Snape, and G. K. Wilcock, "The cholinergic hypothesis of Alzheimer's disease: a review of progress," Journal of Neurology Neurosurgery and Psychiatry, vol. 66, no. 2, pp. 137-147, 1999.
[46] R. Rodriguez-Puertas, A. Pazos, J. J. Zarranz, and J. Pascual, "Selective cortical decrease of high-affinity choline uptake carrier in Alzheimer's disease: an autoradiographic study using $3 \mathrm{H}-$ hemicholinium-3," Journal of Neural Transmission. Parkinson's Disease and Dementia Section, vol. 3, pp. 161-169, 1994.

[47] P. Hammond and S. Brimijoin, "Acetylcholinesterase in Huntington's and Alzheimer's diseases: simultaneous enzyme assay and immunoassay of multiple brain regions," Journal of Neurochemistry, vol. 50, no. 4, pp. 1111-1116, 1988.

[48] E. B. Fishman, G. C. Siek, R. D. MacCallum, E. D. Bird, L. Volicer, and J. K. Marquis, "Distribution of the molecular forms of acetylcholinesterase in human brain: alterations in dementia of the Alzheimer type," Annals of Neurology, vol. 19, no. 3, pp. 246-252, 1986.

[49] E. K. Perry, R. H. Perry, G. Blessed, and B. E. Tomlinson, "Changes in brain cholinesterases in senile dementia of Alzheimer type," Neuropathology and Applied Neurobiology, vol. 4, no. 4, pp. 273-277, 1978.

[50] T. Arendt, M. K. Bruckner, M. Lange, and V. Bigl, "Changes in acetylcholinesterase and butyrylcholinesterase in Alzheimer's disease resemble embryonic development-a study of molecular forms," Neurochemistry International, vol. 21, no. 3, pp. 381396, 1992.

[51] S. Kumar, "Biphasic effect of aluminium on cholinergic enzyme of rat brain," Neuroscience Letters, vol. 248, no. 2, pp. 121-123, 1998.

[52] R. R. Kaizer, M. C. Corrêa, L. R. S. Gris et al., "Effect of longterm exposure to aluminum on the acetylcholinesterase activity in the central nervous system and erythrocytes," Neurochemical Research, vol. 33, no. 11, pp. 2294-2301, 2008.

[53] G. P. Jarvik, E. B. Larson, K. Goddard, W. A. Kukull, G. D. Schellenberg, and E. M. Wijsman, "Influence of apolipoprotein E genotype on the transmission of Alzheimer disease in a community-based sample," American Journal of Human Genetics, vol. 58, no. 1, pp. 191-200, 1996.

[54] S. I. Rapoport, B. Horwitz, C. L. Grady, J. V. Haxby, C. DeCarli, and M. B. Schapiro, "Abnormal brain glucose metabolism in alzheimer's disease, as measured by positron emission tomography," Advances in Experimental Medicine and Biology, vol. 291, pp. 231-248, 1991.

[55] S. Hoyer, "Brain glucose and energy metabolism abnormalities in sporadic Alzheimer disease. Causes and consequences: an update," Experimental Gerontology, vol. 35, no. 9-10, pp. 13631372, 2000.

[56] A.-S. A. Newairy, A. F. Salama, H. M. Hussien, and M. I. Yousef, "Propolis alleviates aluminium-induced lipid peroxidation and biochemical parameters in male rats," Food and Chemical Toxicology, vol. 47, no. 6, pp. 1093-1098, 2009.

[57] S. Sarin, V. Gupta, and K. D. Gill, "Alterations in lipid composition and neuronal injury in primates following chronic aluminium exposure," Biological Trace Element Research, vol. 59, no. 1-3, pp. 133-143, 1997.

[58] M. Nampoothiri, N. D. Reddy, J. John, N. Kumar, G. K. Nampurath, and M. R. Chamallamudi, "Insulin blocks glutamateinduced neurotoxicity in differentiated SH-SY5Y neuronal cells," Behavioural Neurology, vol. 2014, Article ID 674164, 8 pages, 2014.

[59] M. Tsunoda and R. P. Sharma, "Modulation of tumor necrosis factor $\alpha$ expression in mouse brain after exposure to aluminum in drinking water," Archives of Toxicology, vol. 73, no. 8-9, pp. 419-426, 1999. 
[60] H. Takeuchi, S. Jin, H. Suzuki et al., "Blockade of microglial glutamate release protects against ischemic brain injury," Experimental Neurology, vol. 214, no. 1, pp. 144-146, 2008. 


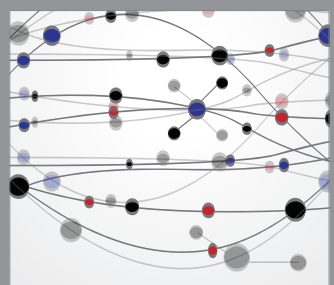

The Scientific World Journal
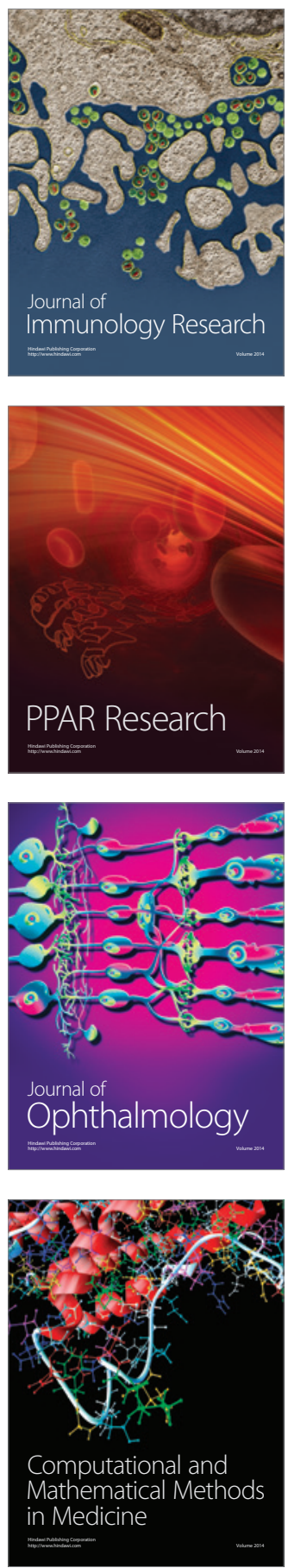

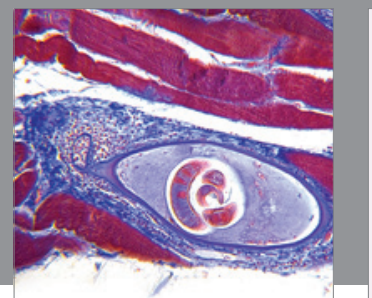

Gastroenterology

Research and Practice
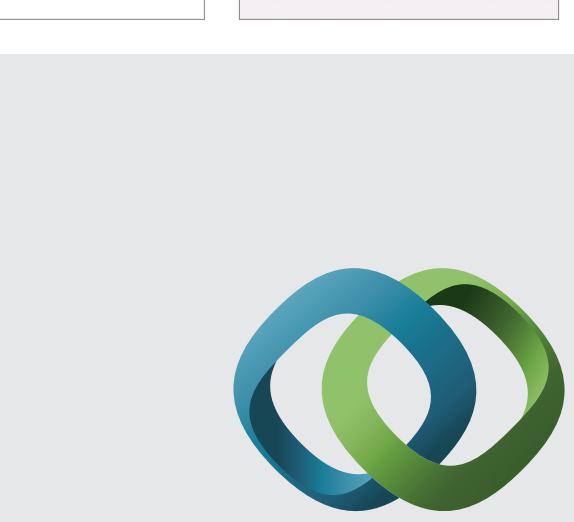

\section{Hindawi}

Submit your manuscripts at

http://www.hindawi.com
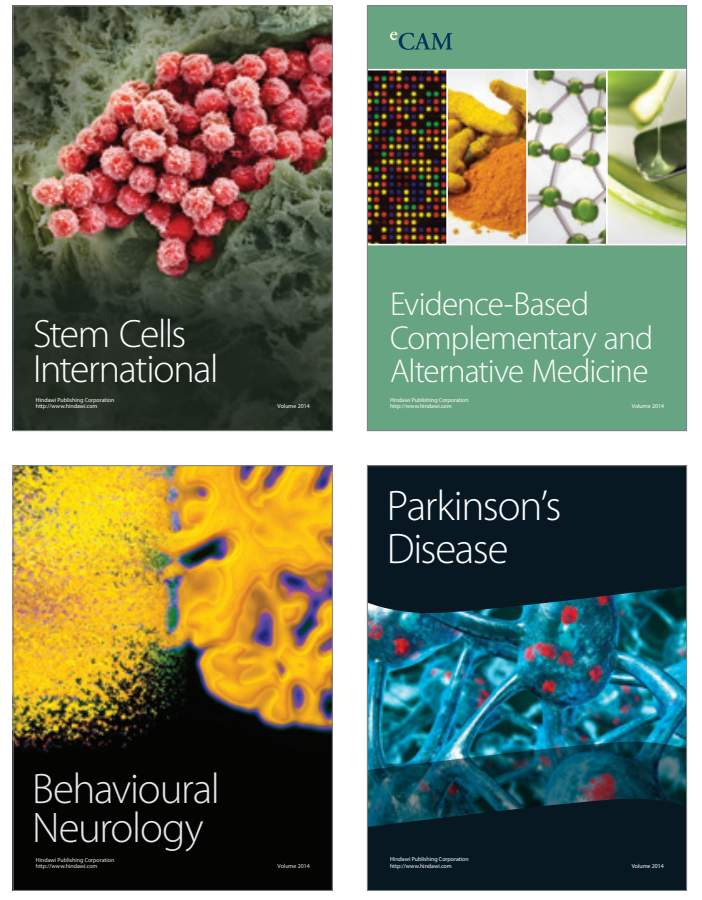
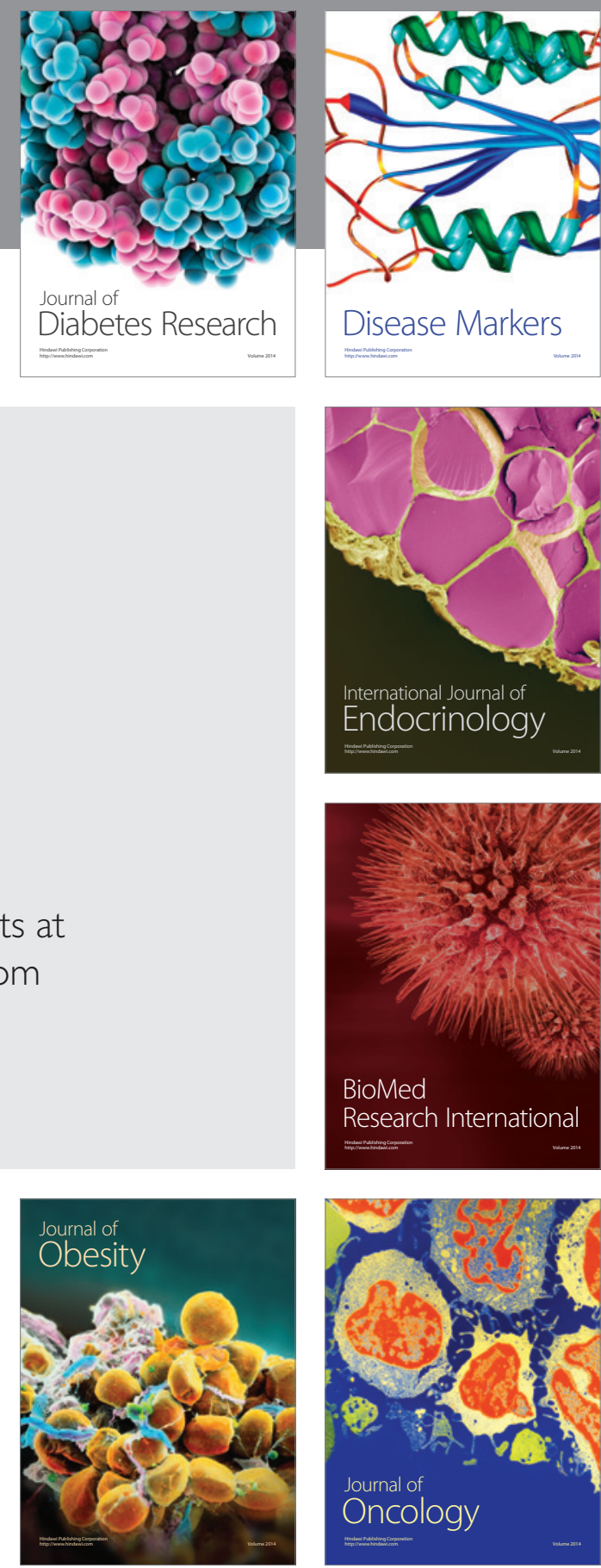

Disease Markers
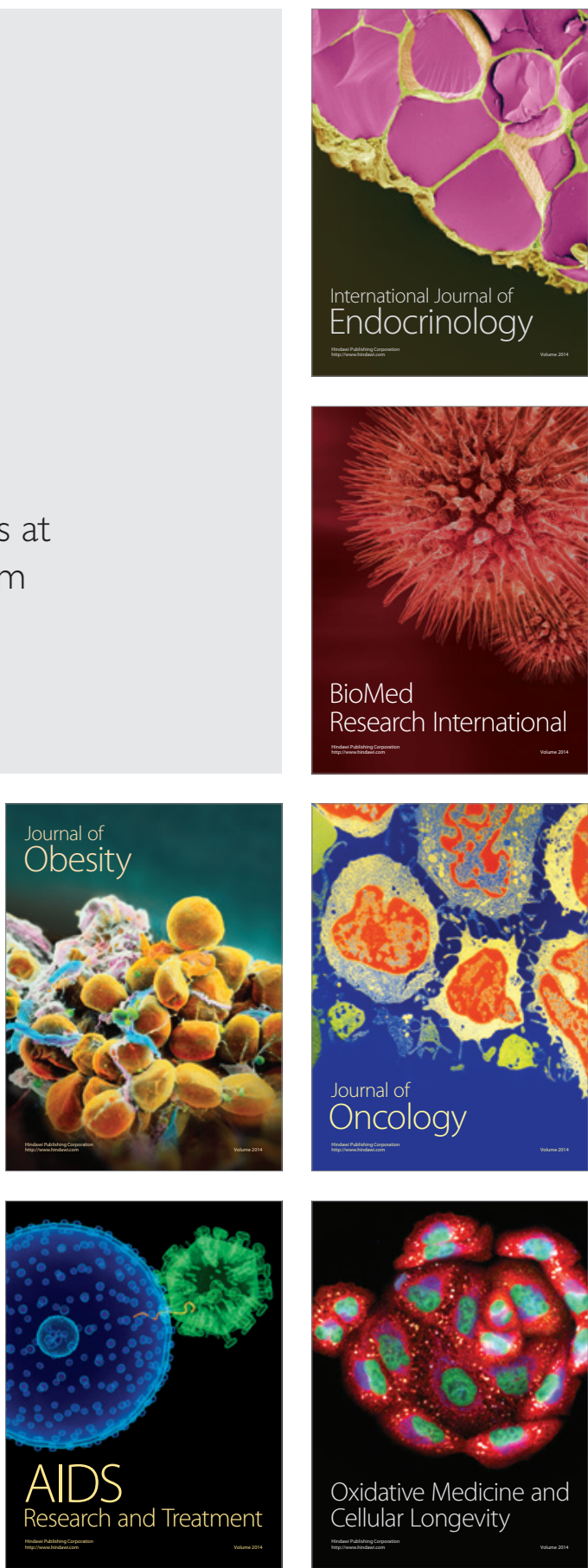